\title{
OS VAZIOS URBANOS E O DIREITO À CIDADE: DESAFIOS DA IMPLEMENTAÇÃO DO IPTU PROGRESSIVO EM CAMPOS DOS GOYTACAZES/RJ
}

\author{
Bianca Siqueira Gonçalves* \\ José Luis Vianna da Cruz**
}

\begin{abstract}
Resumo
Este estudo analisa a cidade como produção social, fruto da ação complexa e conflituosa de agentes sociais, que representam distintos interesses. Discorre sobre a dinâmica capitalista na construção do espaço na cidade e como se organizam as estruturas urbanas. Tendo como cenário a cidade de Campos dos Goytacazes/RJ, apura o papel e a importância do IPTU progressivo no acesso democrático ao solo urbano, conforme preconiza a legislação brasileira, enquanto instrumento de garantia do Direito à Cidade. Foram analisados os fatores que favorecem e permitem a existência de vazios urbanos no perímetro da cidade, em regiões valorizadas e munidas de equipamentos urbanos coletivos, e naquelas a serem valorizadas pela ação pública e/ou privada. Demonstrou-se como a iniciativa privada se apropria dos investimentos públicos para a valorização de seus empreendimentos, o que evidencia a atuação do capital na configuração do ambiente construído. A não aplicação do IPTU progressivo, como um dos instrumentos de cumprimento da função social da propriedade, particularmente no enfrentamento dos vazios urbanos especulativos, demonstra a complexidade dos interesses em jogo. Como o Poder Público municipal vem tratando a questão dos vazios urbanos e do IPTU progressivo na legislação e na prática? Buscou-se compreender alguns aspectos importantes da estrutura e dinâmica do espaço urbano em Campos dos Goytacazes, evidenciando o papel do planejamento urbano, e, neste, reforçar as potencialidades da implementação do IPTU progressivo como meio de reintegrar os vazios urbanos existentes, possibilitando mitigar os impactos da concentração do solo urbano e a especulação imobiliária, fatores agravantes da segregação socioespacial.
\end{abstract}

Palavras-chave: Cidade. Conflitos. Vazios urbanos. Direito à Cidade. IPTU progressivo.

\footnotetext{
* Analista da Secretaria de Fazenda do Estado do Rio de Janeiro; Bacharel em Direito pelas Universidade Estácio de Sá (UNESA); Pós-graduada em Direito Penal e Processo Penal também pela UNESA; Pós-graduada em Direito Tributário (Faculdade Internacional Signorelli); Mestra em Planejamento Regional e Gestão de Cidades pela Universidade Candido Mendes-Campos (UCAM) e Doutoranda em Planejamento Regional e Gestão de Cidades pela UCAM. E-mail: biancasgoncalves@hotmail.com

** Professor permanente do Programa de Mestrado e do Doutorado em Planejamento Regional e Gestão de Cidades Universidade Candido Mendes-Campos (UCAM); Graduado em Ciências Sociais pela Universidade Federal do Rio de Janeiro (UFRJ); Mestre e Doutor em Planejamento Urbano e Regional pelo Instituto de Pesquisa e Planejamento Urbano e Regional (IPPUR/UFRJ); Pós-doutor em Desenvolvimento Territorial e Políticas Públicas pela Universidade Federal Rural do Rio de Janeiro (UFRRJ). E-mail: joseluisvianna@uol.com.br
} 


\section{Introdução}

$\mathrm{O}$ que, à primeira vista, parece ordem é o caos para uma grande parte dos moradores das cidades. O sistema capitalista está gerando graus de desordem inéditos, enquanto alguns economistas o vêm como portador dos elementos para garantir o tão buscado equilíbrio. A cidade capitalista tornou-se uma mercadoria a serviço do capital. Em consequência, o acesso ao solo e aos equipamentos de consumo coletivo é precário ou inexistente para a maioria trabalhadora dos seus habitantes (BOURDIEU, 1989). O privado impõe-se ao público; os interesses econômicos empresariais superpõem-se aos interesses sociais e coletivos.

No capitalismo, a cidade é o resultado no espaço dos processos de produção, circulação e consumo. A criação desse espaço é carregada de contradições e tensões, uma vez que nele estão envolvidos os interesses do capital em seus diversos segmentos, da força de trabalho e do Estado (PIQUET; RIBEIRO, 2001).

A cidade capitalista é o lugar privilegiado de ocorrência de uma série de processos sociais, onde a reprodução social está condicionada pelo processo de acumulação de capital. A urbanização capitalista é, antes de tudo, uma multiplicidade de processos de apropriação do espaço. Para uns, a terra tem valor de uso; para outros, valor de troca. $\mathrm{O}$ valor de uso diz respeito à utilidade social, para atender às necessidades coletivas universais; o valor de troca diz respeito ao uso da cidade, do seu solo e do ambiente construído, para fins de acumulação privada de capital; ou seja, ao uso da cidade como mercadoria, totalmente submetida aos interesses do capital privado empresarial.

A dinâmica mais recente do processo urbano trouxe com ela dramáticas transformações no estilo de vida. As políticas urbanas neoliberais, que ganharam força no Brasil há cerca de duas décadas, vêm sendo decisivas no sentido de definir a (re)estruturação do espaço urbano. Para além do aspecto econômico, as mudanças impulsionadas pela globalização afetam a produção do espaço urbano e atingem diretamente a formulação e legitimação de paradigmas nas políticas urbanas. Dessa forma, a adoção das diretrizes e concepções neoliberais que configuraram as relações entre capital, Estado e sociedade gerou profundas repercussões sobre o lugar e o papel da cidade no processo de acumulação.

Com o neoliberalismo, a cidade passa a ser tratada como espaço direto do capital mediado pela lógica da valorização do capital e da financeirização. Submetida ao movimento espontâneo do mercado, a cidade passa a funcionar como uma verdadeira empresa e como tal passa a ser conduzida (VAINER, 2011). 
$\mathrm{Na}$ formação das cidades, em geral, grandes porções de terra urbanizadas ou não - ficam desocupadas ou sem uso, devido a interesses imobiliários especulativos, circunstâncias ambientais ou de infraestrutura. E essas porções são chamadas de "vazios urbanos", visto que bloqueiam o desenvolvimento equilibrado das cidades, impedem o acesso da maioria da população à terra, à medida em que sua imobilização eleva os preços dos terrenos urbanos. Por isso, esses espaços têm sido uma das questões mais importantes na definição de processos efetivos de planejamento urbano.

Assim, surgem algumas questões: quais os elementos que contribuem para a formação dos espaços territoriais vazios (ou vazios urbanos)? Como os vazios urbanos conseguem sobreviver dentro de um espaço territorial concorrido como é a cidade?

Para compreender o processo de formação dos vazios urbanos, é preciso analisar a ação dos diferentes agentes que produzem o espaço urbano (incorporadores imobiliários, Estado, proprietários dos meios de produção, proprietários fundiários e os grupos sociais excluídos) e identificar quais os interesses que os motivam. É essencial observar as relações sociais desenvolvidas em um determinado espaço e examinar de que modo elas influenciam os contornos desse espaço.

Quando o Estado permite vazios urbanos em áreas povoadas ou localizadas na faixa de expansão urbana da cidade, a capitalização do território urbano prepondera sobre a socialização do espaço, estando as terras à espera da valorização imobiliária para atendimento dos interesses do capital. O que se deseja é justamente o contrário: a promoção pelos governos municipal, estadual e federal de políticas urbanas condizentes com a demanda coletiva e social, por moradia, incluindo todos os elementos da urbanização e do bem-estar universais.

A inserção do capítulo voltado para a política urbana, em especial os artigos 182 e seguintes, na Constituição Federal de 1988; a publicação do Estatuto da Cidade em 2001; e a criação, em 2003, do Ministério das Cidades, demonstram a importância da matéria (BRASIL, 1988, 2001, 2003). Por meio desses órgãos e instrumentos, é delegada aos municípios a condução do ordenamento da cidade em direção ao desenvolvimento e crescimento sustentáveis. Cabe a eles o cumprimento das diretrizes estabelecidas no Plano Diretor, cuja função é o planejamento da cidade direcionado para as questões sociais, econômicas e ambientais, públicas, coletivas. Não se pode perder de vista que a propriedade privada deverá cumprir sua função social.

Com o foco de interesse na questão urbana, centra-se a análise nos vazios urbanos de Campos dos Goytacazes/RJ. A dinâmica que envolve a produção do espaço urbano pode ser vista na cidade de Campos dos Goytacazes, já que, desde a sua fundação, foi sendo construída a partir da 
relação complexa dos diferentes agentes sociais. A cidade cresceu de forma intensa; porém, descontínua. Isso privilegiou os agentes sociais do setor imobiliário. E, conforme a cidade se expande, vazios urbanos evidenciam-se.

O objeto de estudo consiste na relação entre o IPTU progressivo e os elementos contemplados na legislação brasileira sobre o Direito à Cidade, destacando o seu papel na mitigação dos impactos das glebas vazias como obstáculos à consecução desses preceitos, restrito àquelas que se localizam dentro do perímetro urbano do distrito sede de Campos dos Goytacazes.

Quanto ao recorte espacial da área de estudo, o perímetro urbano do distrito sede de Campos dos Goytacazes foi eleito como unidade de análise. Para responder às questões da pesquisa, analisou-se o Plano Diretor (PDMCG/2008) - Lei no 7.972, de 31 de março de 2008 -, a Lei Orgânica, de 15 de julho de 2014, e o Código Tributário Municipal Lei no 4.156, de 16 de setembro de 1983, do referido Município (CAMPOS DOS GOYTACAZES, 1983, 2008, 2014), e suas contribuições para a concretização de função social da propriedade municipal, sendo referências a Constituição Federal de 1988, o Estatuto da Cidade, o Código Civil e as normas editadas pelo Conselho das Cidades e pelo Ministério das Cidades.

Para compreender a origem dos vazios urbanos em Campos dos Goytacazes, a pesquisa demandou a triangulação de dados, com análise do objeto sob as perspectivas documental, legislativa e espacial. Para análise espacial, foram estudados mapas, fotografias e realizadas observações in loco dos vazios urbanos, com captura de imagens. Para identificar quem são os titulares dos espaços vazios da cidade, recorreu-se aos Cartórios de Registro de Imóveis.

Para diagnosticar como se materializa a atuação da Administração Pública, foram analisadas as respostas fornecidas pela Secretaria Municipal de Fazenda às indagações sobre a arrecadação do IPTU, o percentual dos espaços vazios e dos espaços edificados dentro da malha urbana e a implantação do IPTU progressivo, dentre outras informações.

\section{O espaço urbano e o Direito à Cidade}

O Estado capitalista é produto das relações sociais, expressando a estrutura de poder que favorece o capital, e que se exerce, também, nas instâncias político-administrativas, isto é, condensa uma série de articulações (conflituais e não conflituais) de forças sociais. Nas formações sociais capitalistas, a articulação social dominante é determinada pelas relações sociais de produção, e a sua lógica, que penetra desigualmente todo o tecido social, é a lógica do capital (SANTOS, 2008).

Áreas urbanas são locais onde grandes quantidades de trabalho e capital são combinados com pequenas quantidades de terras para produzir 
bens e serviços. Assim, vê-se que a variável econômica está interligada ao funcionamento e à própria existência da cidade. A cidade capitalista é a expressão territorial da socialização contraditória das forças produtivas no modo de produção capitalista. Seu papel é abrigar as atividades econômicas e dar condições ao desenvolvimento da economia. O capital que participa na produção da cidade pode ser público ou privado, e sua utilização viabiliza a transformação do espaço físico urbano. Se por um lado a participação do capital público na produção da cidade viabiliza a infraestrutura urbana, a construção de casas para baixa renda e a renovação urbana; por outro, a participação do capital privado está sempre relacionada à obtenção de lucro.

A organização do espaço decorre de um conjunto complexo de forças, mobilizado por diversos agentes sociais. Os principais agentes estruturantes do espaço são o Estado, os empresários e os moradores (PIQUET; RIBEIRO, 2001). É um processo conflituoso, ainda mais nos espaços ecológicos de densidade social muito diversificada.

Conforme Corrêa (2005), a produção e o consumo do espaço urbano ocorrem a partir da ação dinâmica e, ao mesmo tempo, complexa de agentes sociais concretos. A paisagem refletirá a materialização dos distintos interesses da iniciativa privada empresarial, dos grupos sociais desfavorecidos, da sociedade como um todo e dos grupos presentes no Poder Público. São vários os agentes que atuam na produção do espaço urbano na cidade capitalista. Vê-se que a ocupação do território, o sistema urbano e a própria cidade são um "subproduto" das articulações dos interesses hegemônicos (PIQUET, 2007).

Vivemos progressivamente em áreas urbanas divididas e tendentes ao conflito, o que resulta em uma cidade que está se dividindo em diferentes partes segregadas, manifestadas em condomínios fechados de classe média e alta e, por outro lado, em favelas e áreas apartadas, desprovidas de infraestrutura adequada à ocupação e com sérios problemas de mobilidade. O espaço é valorizado em função dos interesses de uso (para transporte, para atividades econômicas, dentre outras).

As ações e estratégias dos principais agentes e/ou sujeitos produtores do espaço urbano nos levam a enxergar com maior nitidez os processos reprodutores de desigualdade socioespaciais, de forma específica no que se refere à apropriação e ao uso desigual do solo urbano. A complexidade como se relacionam os agentes sociais torna a produção do espaço urbano dinâmica, desigual e contraditória. A desigualdade manifesta-se a partir de diversas esferas, dentre elas, a espacial. É no espaço que os agentes se localizam e se deslocam (VASCONCELLOS, 2000, p. 199).

Se o solo urbano não tivesse valor e não gerasse renda, evidentemente não despertaria interesse por parte da iniciativa privada e dificilmente haveria desenvolvimento na cidade. Por isso, é fundamental que o Poder 
Público administre o conflito entre o interesse geral e o aumento do valor e renda do solo por parte de alguns interessados privados, de tal forma que o objetivo principal seja o ordenamento urbano sob esses princípios. O interesse geral não pode ser preterido em prol dos interesses econômicos de alguns. Caso o Poder Público não consiga administrar o conflito entre o interesse geral e os interesses econômicos de determinado grupo, a ocupação desordenada do solo e a especulação imobiliária descontrolada dominarão a expansão urbana.

No estudo do processo de formação do espaço urbano de uma cidade, deve-se atentar para o fato de que, na medida em que o espaço se organiza - por meio de arranjos e combinações entre variáveis e interesses -, é responsável pelo direcionamento social do espaço a variável ou os interesses que tiverem mais influência sobre os demais. Assim, se os interesses dos agentes do sistema econômico preponderarem, teremos a variável econômica conduzindo a formação e a organização da sociedade, ou seja, predominarão os interesses empresariais do lucro.

Segundo Singer (1980), os vazios urbanos acarretam a subutilização dos serviços urbanos, ao manter vagos, à espera de valorização, lotes que dão acesso a pelo menos parte deles. A ironia da situação é que, ao mesmo tempo, cresce a parcela da população que não tem recursos para realmente habitar. Nesse ponto, é preciso integrar o vazio urbano à dinâmica da cidade, à sociabilidade da cidade e à garantia do Direito à Cidade.

Segundo Lefebvre (2001), o Direito à Cidade é também o direito à apropriação, sendo uma forma superior dos direitos (engloba o direito à liberdade, à individualização na socialização e o direito ao morar). $\mathrm{O}$ direito à apropriação, bem distinto do direito à propriedade, está, portanto, implícito no Direito à Cidade.

Sobre as raízes desse direito, é necessário buscar os referenciais no ano de 1967, ano em que Lefebvre escreveu a obra manifesto "Direito à Cidade". Trata-se de um conceito acadêmico e de luta social. A cidade é vista como obra coletiva, onde predomina o valor de uso; é um direito que deve ser exercido em sua plenitude e dispensado a todos.

Para Lefebvre (2006), o Direito à Cidade se afirma como um apelo, como uma exigência e o urbano é um lugar de encontro, com prioridade do valor de uso. Assim sendo, "não se pode evitar o conflito" na medida em que o "urbano se baseia no valor de uso", irredutível e imanente ao humano (LEFEBVRE, 2006).

Direito à cidade implica a ótica predominante do valor de uso, para que todos possam usufruir da riqueza socialmente produzida. Ou seja, é uma forma de alterar a dinâmica da cidade como mercadoria (LEFEBVRE, 2001; HARVEY, 2001). Ao invés de ver cada pedaço da cidade como valor de troca, é preciso pensar a cidade, em sua totalidade, como valor de uso, dar 
uma finalidade social a ela e privilegiar sua função enquanto catalizadora de direitos sociais. $\mathrm{O}$ Direito à Cidade se torna bem mais do que o direito individual de ter acesso a serviços públicos de qualidade, significa ter mais liberdade de viver e experimentar os espaços que criamos e recriamos constantemente.

$\mathrm{O}$ conceito de Direito à Cidade, desse modo, não pode ser compreendido apenas como o direito de visita ou de retorno às cidades tradicionais. Para Lefebvre (2001, p. 134), "direito à cidade se manifesta como forma superior dos direitos" e engloba os direitos “à liberdade, à individualização na socialização, ao habitat e ao habitar”. Nesse sentido, “[...] o direito à obra (à atividade participante) e o direito à apropriação (bem distinto do direito à propriedade), estão implicados no direito à cidade". É a condensação do direito à vida urbana, transformada, renovada.

O Direito à Cidade é compreendido para além do usufruto de benefícios públicos urbanos: manifesta-se principalmente como o direito de modificação do espaço urbano. Ao compreender a cidade enquanto um produto que gera lucro (feita para o consumidor economicamente privilegiado), a mudança planejada para a cidade, muito embora em tese propicie melhores condições da vida cotidiana para boa parte dos moradores, reforça a segregação urbana de numerosa fatia da população.

Assim, o Direito à Cidade é também o direito de participar da construção do projeto de cidade, que envolve seus habitantes (os diversos atores sociais) e o Poder Público. Em contrapartida, a existência da pressão econômica tende a aumentar as desigualdades socioespaciais, resultantes de determinadas políticas públicas em prol de determinados grupos sociais.

Os vazios urbanos são a face visível da desigualdade socioespacial e da concentração do solo nas cidades, pois permitem a formação de estoques fundiários para forçar a valorização, sendo um dos instrumentos de especulação imobiliária. São propriedades que descumprem a função social, na medida em que interrompem a continuidade do tecido urbano, impedem a integração da cidade para dentro e para fora e são um obstáculo à apropriação coletiva do espaço urbano.

A existência de vazios urbanos retrata o desequilíbrio social e a inércia estatal na aplicação da legislação urbana. Grande parte das cidades que apresentam fatores de segregação socioespacial são dotadas de vazios urbanos em regiões valorizadas no mercado de imóveis, caminhando na contramão do aproveitamento adequado e ordenado do solo urbano. Muitos proprietários mantêm terrenos sem utilização "de olho" na valorização futura e que é certa frente à escassez de terra. Outros não agem com má fé; mas, por falta de iniciativa e de penalização, não tomam as providências para dar uso aos seus imóveis ou vendê-los, prejudicando toda a cidade. Agrava o problema a inércia frequente do Poder Público 
municipal quanto ao instituto da desapropriação. Além da localização, o que valoriza um imóvel na cidade são os investimentos públicos e privados. O proprietário que retém terrenos se apropria desse esforço coletivo; por isso, deve ser penalizado. O objetivo é conferir aos imóveis urbanos ociosos uma destinação voltada a beneficiar à coletividade.

A Constituição Federal de 1988, ao lado da inviolabilidade do direito de propriedade, limita tal direito na exigência de que a propriedade deverá atender à sua função social: "A propriedade atenderá a sua função social". Essa é a prescrição do inciso XXIII do artigo 5o (BRASIL, 1988). São os termos de uma máxima expansível a todos os meandros do ordenamento jurídico pátrio não somente como relação, mas também como sanção.

A função social da propriedade é um conceito indeterminado e até impreciso. O constituinte originário atribuiu ao Plano Diretor importante tarefa de delimitá-la. A Constituição Federal de 1988 foi pioneira ao estabelecer um capítulo inteiro sobre Política Urbana, dando aos Municípios a capacidade legislativa de elaboração dos Planos Diretores. Assim, ao Município foi dado o poder de delimitação legal via Plano Diretor do conteúdo da função social da propriedade.

\section{Análise da atual dinâmica da malha urbana de Campos dos Goytacazes}

Neste estudo, por unidade de análise, escolheu-se o perímetro urbano do distrito sede de Campos dos Goytacazes, município localizado no norte do Estado do Rio de Janeiro e que, segundo o Censo Demográfico IBGE 2010, possui no total 463.545 habitantes, sendo 418.565 residentes na zona urbana. Com área total de $4.027 \mathrm{Km}^{2}$ de extensão territorial, delimitou-se a área de estudo ao perímetro urbano desse município. A escolha originou-se a partir da observação da distribuição da malha urbana, onde se constata a existência de importantes vazios, na área mais adensada em termos populacionais e dos investimentos públicos e privados em equipamentos, infraestrutura e serviços. A estrutura urbana da cidade de Campos dos Goytacazes possibilita o estudo empírico do processo de capitalização do espaço urbano e da atuação dos atores públicos e privados na construção do espaço.

Considerando as variáveis sociais que contribuem para a formação do espaço, fez-se necessário pesquisar os vazios urbanos de Campos dos Goytacazes para compreender o que os causa e quais consequências geram para a integração do espaço da cidade.

Os espaços vazios no perímetro urbano de Campos dos Goytacazes são, em sua maioria, formados por glebas de terras das usinas de cana de açúcar e álcool, de fazendeiros e de investidores que se localizam nos 
arredores da cidade. A partir do Plano Diretor de 1979, com a expansão do perímetro urbano como consequência do crescimento da cidade, muitas dessas propriedades, antes consideradas rurais, passaram a compor o cenário da cidade e se localizar dentro do espaço urbano. É interessante observar que, no século XIX, as usinas se localizavam nos vazios territoriais que se alojavam no entorno da cidade. $\mathrm{Na}$ segunda metade do século $\mathrm{XX}$, após o fechamento de algumas usinas, como consequência da crise econômica do setor, associado ao crescimento do perímetro urbano, esses locais passaram a ser os grandes vazios dentro da cidade.

Da análise do Mapa dos Vazios Urbanos do Distrito Sede (PINHEIRO; ALIPRANDI, 2015), é possível constatar que a malha urbana da cidade contém significativo número de vazios urbanos. Cabe relembrar que se encontram dentro do perímetro urbano delimitado pelo PDMCG/2008 as terras das usinas São João, São José, Santo Antônio, Queimado, Cambaíba, Cupim, Novo Horizonte, Paraíso, Santa Cruz, Santo Amaro e Sapucaia, bem como as propriedades de antigas fazendas e as propriedades dos atuais investidores.

A título de exemplo, descreve-se a seguir a atual situação das terras da Usina do Queimado. Localizadas na Avenida Arthur Bernardes, são grandes espaços da paisagem e servem de pastagem, para camuflar a utilização dessas glebas como reserva de valor para investidores e empreendedores imobiliários, que, possivelmente, transformarão essas glebas, esses vazios urbanos, em empreendimentos imobiliários como loteamentos populares ou condomínios fechados.

É oportuno, também, analisar o estado das terras da Usina Sapucaia. Localizadas à margem esquerda do Rio Paraíba do Sul e subindo seu leito pela BR-356, dentro do Distrito Sede (10 Distrito), estendem-se até o município vizinho de Cardoso Moreira. Possuem extensão de cerca de 2.000 alqueires geométricos e em seu território foram construídos bairros como Parque Aldeia, o conjunto do programa habitacional da prefeitura de Campos dos Goytacazes "Morar Feliz Parque Aldeia" e o bairro Parque Cidade Luz.

Nas terras dessa usina, é expressiva a quantidade de áreas alagadiças como consequência da existência de lagoas e brejos. Os projetos urbanísticos (que priorizavam a área central da cidade) e as legislações adotadas ao longo do tempo pelo Poder Público Municipal comprometeram a valorização dessas terras, estigmatizando-as como periferia. Talvez esse seja o motivo de não se encontrar condomínios de classe média alta e alta nesses territórios. Na margem sul do Rio Paraíba, estão as terras da predita Usina do Queimado, da Usina Cambaíba e da Usina Santo Antônio, situadas nas áreas de expansão da cidade, categoria de terra mais valorizada pelo mercado imobiliário. 
Os vazios urbanos de Campos dos Goytacazes não pertencem apenas às famílias dos usineiros, mas também a fazendeiros e a investidores, tais como Ari Pessanha e Arthur Marinho.

Dentre os investidores, cite-se o Grupo Othon que, apesar de dedicarse ao setor hoteleiro, diversifica seus negócios com investimentos em usinas da região Norte Fluminense (como a Usina Cupim, localizada no Distrito Sede). Investiu, também, na região do bairro Vila da Rainha - localizado entre a Universidade Estadual Norte Fluminense (UENF), o Canal Cambaíba, às margens do Rio Paraíba do Sul e do bairro Jockey). Nessas terras, vários empreendimentos foram feitos, como: o Clube Saldanha da Gama, o Centro de Eventos Populares (CEPOP) e os condomínios Palm Spring e Remanso do Paraíba.

Verifica-se que a malha urbana da cidade em estudo é bem centralizada e em constante crescimento. Constata-se verticalização e a busca de aproveitamento máximo do terreno disposto.

A área central possui o tecido urbano mais adensado da cidade. Corresponde ao centro histórico e aos bairros mais ocupados e mais valorizados de Campos dos Goytacazes.

O Distrito Sede ocupa o maior território urbano da cidade, compreendendo praticamente todo o perímetro urbano considerado pelo Plano Diretor Municipal (PDM 2008) e, por sua vez, concentra a maior parte da população campista.

A observação do Mapa de Verticalização (PINHEIRO; ALIPRANDI, 2015) permite concluir que o Distrito Sede possui o maior índice de ocupação e que as quadras são densamente ocupadas. Possui o maior índice de verticalização e crescimento populacional do município, referente aos imóveis que possuem sete pavimentos ou mais. Pode-se observar uma concentração de ocupação dos espaços próximos ao centro antigo. Segundo a Secretaria de Fazenda do Município de Campos dos Goytacazes (SFM), são 9.843 imóveis construídos no Centro e 3.505 imóveis construídos no "novo centro", que é a região da Pelinca. Por via de consequência, há o aumento na verticalização visível. $\mathrm{O}$ adensamento acarreta a supervalorização imobiliária e a saída de moradores com menor renda para as margens do centro urbano.

Quanto aos vetores de crescimento, identifica-se no sentido Goytacazes/Jockey (Leste) os Conjuntos do Programa Morar Feliz e empreendimentos privados. Da Avenida Arthur Bernardes ao Shopping Boulevard (Sul), constata-se a presença de condomínio e loteamentos. Ao Norte, no sentido da BR-101 em direção à Vitória, há o aeroporto e estabelecimentos de abastecimento. Não se identifica expressivo crescimento, muito embora a recente opção pela construção de conjuntos habitacionais populares de grande porte (mais de 500 moradias) na área 
tende a valorizar os terrenos e a demandar a implantação de infraestrutura pelo Poder Público municipal, o que poderá configurar um novo vetor de urbanização. No sentido Oeste, fica a comunidade da Aldeia e há tímido crescimento.

Embora a Constituição Federal não preveja sobre o combate à especulação imobiliária, cita instrumentos coercitivos (também chamados de penalidades constitucionais), que têm essa finalidade.

O Estatuto da Cidade é um instrumento jurídico que absorve conceitos e linhas de pensamento teórico que, em linhas gerais, vão na contracorrente da adesão ao projeto de cidade transformada em mercadoria.

Da leitura da lei, depreende-se que o Estatuto da Cidade inova quando trata da ocupação do solo, não somente considerando a base material da cidade, ou seja, as necessidades de infraestrutura, de equipamentos públicos e de prestação de serviços para todos os cidadãos. O que o Estatuto da Cidade determina é que a ocupação do solo urbano se realize objetivando a melhoria dos assentamentos humanos, o que requer políticas integradas que propiciem a educação, o trabalho, o aumento da capacidade aquisitiva, $o$ acesso à moradia, à segurança jurídica da posse e à participação democrática. Criou, ainda, uma série de instrumentos para que a cidade possa buscar esses objetivos, sendo o principal o Plano Diretor. Prevê, ainda, outros instrumentos urbanísticos que têm no combate à especulação imobiliária e na regularização fundiária dos imóveis urbanos seus principais objetivos.

A tributação sobre a propriedade imobiliária foi um dos principais instrumentos jurídicos criados para controlar o processo de expansão urbana submetida ao princípio da função social da propriedade; a tributação sobre a propriedade imobiliária se tornou um instrumento de política urbana. O IPTU progressivo é um instrumento de minimização da segregação urbana, de democratização do Direito à Cidade, do acesso ao solo urbano e da melhoria da qualidade de vida da cidade. Em termos concretos, uma vez tendo sido introduzida a progressividade do imposto, após notificação, feita pelo Município, da obrigatoriedade de edificação ou parcelamento, e, transcorrido determinado prazo, se o proprietário não tomar qualquer providência, o valor lançado do IPTU virá a sofrer uma constante majoração anual, sob a forma de crescente porcentagem de acréscimo.

Segundo o artigo $7{ }^{\circ}$ do Estatuto da Cidade (Lei n ${ }^{\circ}$ 10.257/2001), a majoração da alíquota terá o prazo de cinco anos consecutivos (BRASIL, 2001). O valor da alíquota a ser aplicado a cada ano será fixado em lei específica e não excederá a duas vezes o valor referente ao ano anterior, respeitada a alíquota máxima de $15 \%$. Decorridos cinco anos de cobrança do IPTU progressivo sem que o proprietário tenha cumprido a obrigação de parcelamento, edificação ou utilização, o Município poderá proceder à desapropriação do imóvel, com pagamento em títulos da dívida pública. 
1 Cumpre registrar que no texto deste Plano Diretor não há a previsão de prazo para a regulamentação dos instrumentos não autoaplicáveis, como o caso do IPTU progressivo.
Para que os instrumentos de gestão urbana possam ser utilizados pelo Município para fazer valer a função social da propriedade, é necessário que estejam não apenas previstos no Plano Diretor, mas também em legislação específica que os regulamentem. Apesar da preocupação constitucional, grande parte dos municípios não utiliza os instrumentos de controle do uso do solo instruídos pela norma.

Seguindo as disposições da Constituição Federal e do Estatuto da Cidade, Campos dos Goytacazes revisou o Plano Diretor então existente, sancionado pela Lei no 5.251, de 27 de dezembro de 1991. Houve a promulgação da Lei no 7.972 , de 31 de março de 2008, que instituiu o novo Plano Diretor de Campos dos Goytacazes. Contudo, as transformações urbanas e sociais foram pouco expressivas. É que, embora presentes no texto do Plano Diretor, os instrumentos e as disposições da legislação federal não foram regulamentados ${ }^{1}$, o que impede a efetivação em Campos dos Goytacazes da política urbana instituída no Brasil. No que tange à política urbana, Campos dos Goytacazes ainda não conhece o resultado do seu novo Plano Diretor, incapaz de produzir transformações.

É evidente que o aspecto legal não garante o ordenamento da cidade. É preciso mais, para que se atenda ao interesse público e se alcance qualidade de vida para todos. Percebe-se claramente que o Estatuto da Cidade impulsiona o Poder Público a instituir espaços urbanos mais qualitativos e menos excludentes. Assim, da premissa do alcance da função social da propriedade é que deveria surgir a política urbana da cidade, com seus instrumentos de gestão, controle e fiscalização.

Em sede de planejamento e gestão das cidades, falar em tributos não é, necessariamente, falar em arrecadação ao fisco. Nessa específica seara, a tributação urbana ganha status extrafiscal ao transformar-se em importante instrumento para regulação urbanística e minoração de desigualdades no direito pleno à cidade. Assim, para a eficácia do cumprimento das funções sociais da cidade e da propriedade privada, outros objetivos deverão ser alcançados, tais como uma maior atenção e regulação à expansão urbana, a existência de meios hábeis de caráter compensatório para distribuição da renda urbana, bem como o desestímulo, quiçá impedimento, a práticas empresariais contrárias à função social da propriedade. $\mathrm{O}$ objetivo não é arrecadar mais, mas garantir o cumprimento da função social dos imóveis ociosos, bem como ampliar a oferta de terrenos bem localizados. Com isso, há um impacto significativo nos valores imobiliários.

Um estudo de Carvalho Júnior (2010) aponta o Brasil como um país que tributa pouco a propriedade imobiliária: algo como $0,4 \%$ do $\mathrm{PIB}$, percentagem bem inferior aos $0,8 \%$ cobrados em outros países de renda semelhante, como a África do Sul e Argentina. Também é baixa a participação destes impostos na arrecadação local: aproximadamente 6\%, 
pouco quando se compara com os $25 \%$ na Nova Zelândia, França e Israel, sendo que na África do Sul essa percentagem alcança $17 \%$.

Tal desempenho compromete não apenas o aspecto arrecadatório do imposto, mas também o papel extrafiscal que poderia desempenhar na política urbana. Citando Smolka e Schechinger (2005), Carvalho Júnior (2010, p. 46) observa que "[...] países ou municípios que tenham uma tributação imobiliária ativa, conseguem regular de melhor forma o preço da terra, o acesso à habitação e prevenir melhor a informalidade que se traduz em favelas e outros assentamentos precários”.

Ainda acompanhando o citado estudo, Carvalho Júnior considera que a baixa tributação efetiva no Brasil decorre menos da política de alíquotas do tributo e mais da ineficiência administrativa do aparelho fazendário. No Brasil, os tributos imobiliários pesam sobre a propriedade do bem, cujo valor é arbitrado pelo Poder Público. Em cidades que experimentam crescimento econômico, as Prefeituras enfrentam muitas dificuldades técnicas (sem mencionar as dificuldades de ordem política) para atualizarem as plantas de valores imobiliários.

Há mais: a desatualização das plantas genéricas de valores (PGV). O Superior Tribunal de Justiça (STJ) decidiu que o reajuste dessas plantas deve ser aprovado pelas Câmaras de Vereadores dos Municípios. A dificuldade política de atualizá-las leva os executivos municipais a abdicarem dessa atualização, preferindo apenas reajustar os valores pelo índice de correção monetária, por meio de ato administrativo, sem a oitiva do legislativo municipal.

Evidentemente, a questão do acesso ao solo urbano e a desconcentração fundiária não se esgota com a implementação do IPTU progressivo. Sem dúvida, sob o ângulo temporal, a progressividade do IPTU diz respeito, especificamente, à finalidade de coibir a especulação imobiliária com terrenos desocupados ou subutilizados. É com a progressividade no tempo que, além de ficar reforçada a dimensão de extrafiscalidade do IPTU (ou seja, a sua natureza não restrita a uma mera função tributária e arrecadadora), é estabelecida a sua função disciplinadora, na medida em que se dedica ao objetivo constitucional de garantia da "função social da propriedade".

Poucos instrumentos são tão necessários à tarefa de promover o desenvolvimento urbano quanto o Imposto Predial e Territorial Urbano (IPTU) progressivo no tempo, notadamente nas cidades de países periféricos - ou semiperiféricos, como o Brasil. O IPTU colabora decisivamente para a tarefa de imprimir maior justiça social nas cidades caracterizadas, simultaneamente, por fortíssimas disparidades socioespaciais e uma especulação imobiliária desenfreada. Enfim, graças às suas potencialidades de coibição da atividade especulativa em larga escala e de geração de recursos direcionáveis para a dotação de infraestrutura e regularização 
fundiária de áreas residenciais segregadas, esse imposto, como poucos, é capaz de colaborar tanto para evitar a formação de vazios urbanos e o problema da "urbanização em saltos" quanto para superar ou, ao menos, minorar a espoliação urbana.

A cidade, vista pelo ordenamento jurídico pátrio, é composta de leis tipicamente territoriais - tais como o Plano Diretor, a Lei Orgânica e a Lei de Zoneamento do Município -, sendo pensada, em termos gerais, via Estatuto da Cidade (BRASIL, 2001), o qual apresenta princípios, diretrizes e instrumentos de intervenção no solo urbano, no sentido de que o habitat humano seja um espaço que promova dignidade a todos os seus habitantes, conforme normatiza a Constituição Federal.

$\mathrm{Na}$ formulação e implementação de políticas urbanas, deve-se promover o uso socialmente justo, prevalecendo o interesse social e cultural sobre o individual de propriedade. Logo, o Direito à Cidade deve ser exercido dentro dos limites da sustentabilidade e da justiça social. E, no confronto entre o individual e o coletivo, deve prevalecer o bem comum. Sabe-se que fazer valer o bem comum, no que diz respeito ao direito de propriedade, é fazer valer critérios constitucionais do exercício desse direito, ainda que seja necessário combater interesses poderosos de mercado e aplicar instrumentos legais "antipáticos", como o IPTU Progressivo no Tempo, que é um instrumento de poder; afinal, optar pela sua aplicação é uma tomada de decisão que afetará grupos influentes da sociedade.

O IPTU Progressivo no Tempo é o segundo na sequência dos instrumentos coercitivos que podem ser utilizados pelo Poder Público Municipal, segundo a escala prevista no $\S 4^{\circ}$ do artigo 182 da CF (BRASIL, 1988) e é regulado na Seção III do Estatuto da Cidade (BRASIL, 2001).

O Supremo Tribunal Federal também prestou delineamentos sobre a temática ao consolidar o entendimento da progressividade da alíquota no tempo quando para o cumprimento da função social da propriedade. $\mathrm{O}$ enunciado sumular $n^{\circ} 668$ diz que: "É inconstitucional a lei municipal que tenha estabelecido, antes da EC 29/2000, alíquotas progressivas para o IPTU, salvo se destinada a assegurar o cumprimento da função social da propriedade urbana" (STF, 2003, [s. p.]).

Por que as desigualdades socioespaciais não desaparecem? O equilíbrio social e da organização espacial não passa de um discurso tecnocrático, impregnado de ideologia. Viu-se que a ação dos agentes sociais que fazem e refazem a cidade ocorre dentro de um marco jurídico que regula a atuação deles. Esse marco não é neutro, refletindo o interesse dominante de um dos agentes, e constituindo-se, em muitos casos, em uma retórica ambígua, que permite que haja transgressões de acordo com os interesses do agente dominante. Há, entretanto, denominadores comuns que os unem: um deles é a apropriação de uma renda da terra. Por outro lado, a 
ação desses agentes serve ao propósito dominante da sociedade capitalista, que é o da reprodução das relações de produção, implicando a continuidade do processo de acumulação e a tentativa de minimizar conflitos de classe. Assim, a cidade, com tudo o que ela representa em termos produtivos e de local da reprodução da força de trabalho, cresce ao sabor dos interesses privados (PIQUET; RIBEIRO, 2001). As decisões acerca da urbanização são decisões políticas. E tais decisões, no Brasil, têm peculiaridades advindas da relação sociedade e Estado. Os processos decisórios acabam por ser influenciados por padrões estruturadores e organizadores de tais relações.

Com a publicação do PDMCG/2008 - Lei no 7.972/2008, publicada sete anos após o Estatuto da Cidade - Lei no 10.257/2001 -, houve o cumprimento formal das determinações do Estatuto da Cidade e da Resolução no 34 do Conselho das Cidades.

Constata-se que o Plano Diretor do Município de Campos dos Goytacazes, na Seção II ("Dos Instrumentos Compulsórios e Sucessivos”), Subseção I, trata do "Parcelamento, Edificação ou Utilização Compulsórios". Na Subseção II, dedica-se ao "IPTU Progressivo no Tempo". Ao longo da Subseção III, trata da "Desapropriação com Pagamento em Títulos da Dívida Pública".

A Lei Orgânica do Município de Campos dos Goytacazes, promulgada em 15 de julho de 2014, dispõe sobre a Política Urbana em seu Capítulo IV (que é uma repetição ipsis litteris do Capítulo III da Lei Orgânica sucedida - promulgada em 28 de março de 1990).

É interessante destacar que o Código Tributário Municipal, de 16 de setembro de 1983 (alterado pelas Leis Municipais no 4.241/84, 4.348/84, 4.368/84, 4.587/86, 4.683/87, 4.698/87, 4.848/89, 4.983/90, 4.987/90, $4.988 / 90,5.137 / 90,5.138 / 90,5.238 / 91,5.250 / 91,5.252 / 91,5.526 / 93$, 5.537/93, 5.538/93, 6.051/95, 6.297/96, 6.299/96, 6.310/96, 6.406/97, 6.506/97, 6.510/97, 6.712/98, 6.753/99 e 7.020/00), prevê sobre o IPTU nos artigos 110 a 120 , mas nada menciona sobre a progressividade do imposto no tempo.

Embora haja previsão no Plano Diretor e na Lei Orgânica do Município em estudo, carecem os instrumentos de regulamentação, cujo prazo de cumprimento não foi estabelecido nos textos legais.

Segundo resposta concedida pela Secretaria de Fazenda do Município de Campos dos Goytacazes (SFM) ao requerimento formulado pelos pesquisadores no ano de 2016, o IPTU correspondeu a $24,9067 \%$ das receitas municipais, o que demonstra uma expressiva importância desse tributo. O Poder Público municipal admitiu que o IPTU progressivo não é aplicado no município de Campos dos Goytacazes, “[...] porém está em curso uma comissão para a implementação do IPTU progressivo no ano de 2017” (SFM). 
2 Informações concedidas por Dayse Helena de Oliveira C. Bragança, Assessora Especial da Secretaria de Fazenda do Município de Campos dos Goytacazes ao tempo da realização da pesquisa (2016).
Quando perguntada sobre o percentual do território, na área urbana da cidade de Campos dos Goytacazes, que se encontra atualmente sem edificação, a SFM respondeu² apresentando uma tabela dos imóveis edificados, o que evidencia que não há uma base de dados sobre o percentual do território urbano não edificado. É urgente essa criação, pois tais dados prévios são essenciais para viabilizar a aplicação do IPTU progressivo.

Certo é que a falta de regulamentação dos instrumentos coercitivos que existem para dar efetividade à função social da propriedade não é uma questão a ser enfrentada apenas pelo Município de Campos dos Goytacazes. Santos (2014), ao analisar a tributação imobiliária no Brasil, selecionou municípios fluminenses com mais de 100 mil habitantes, tendo como critério de seleção o tamanho da população e as pressões demográficas derivadas do crescimento populacional mais intenso do que a média estadual. Foram selecionados sete municípios com as maiores taxas de crescimento demográfico: Angra dos Reis, Araruama, Cabo Frio, Itaboraí, Macaé, Maricá e Rio das Ostras. Além desses, foram incluídos também a capital estadual e três municípios da região metropolitana cuja população está próxima de um milhão de habitantes (São Gonçalo, Duque de Caxias e Nova Iguaçu), por enfrentarem maior demanda por investimento público e ordenamento urbanístico.

Santos (2014) verificou que o IPTU progressivo no tempo está previsto expressamente na legislação de todos os municípios pesquisados, nas leis orgânicas, nos Planos Diretores ou nos códigos tributários. Ressaltou que a exigibilidade concreta do IPTU progressivo está condicionada à sua previsão expressa nos Planos Diretores e à fixação de três condições de eficácia, que são: a) a demarcação das áreas de incidência; b) a caracterização de quando um imóvel é considerado não edificado, subutilizado ou não utilizado, isto é, quando não cumpre sua função social; c) a fixação de alíquotas progressivas para o período de cinco anos, com limite máximo de $15 \%$ sobre o valor do bem para não caracterizar confisco.

Além disso, Santos (2014) constatou que nenhum dos municípios analisados está em condições de aplicar o IPTU progressivo no tempo, ainda que a maioria tenha introduzido em sua legislação a possibilidade de utilização desse instrumento de política urbana. Mesmo Itaboraí, prevendo as condições de exequibilidade desse instrumento urbanístico, disciplinou de maneira ilegal a progressividade por um período de nove anos, embora o Estatuto da Cidade estabeleça cinco.

A autora concluiu, também, que a variada normatividade do IPTU para fins extrafiscais não apresenta relação com a capacidade de arrecadação fiscal do tributo nos municípios. Algumas possibilidades de uso extrafiscal são exploradas por municípios de elevada incidência de pobreza (como os três localizados na periferia da metrópole carioca, enquanto aqueles 
que apresentaram maior crescimento demográfico associado à baixa incidência de pobreza pouco utilizam o instrumento tributário para fins de ordenamento urbanístico) (SANTOS, 2014).

Os municípios do Estado do Rio de Janeiro estão localizados no epicentro da vida econômica, política e cultura do Brasil. Não podem alegar desconhecimento dos instrumentos normativos que estão à sua disposição para ordenar o uso do solo. De acordo com Santos (2014, p. 110), “[...] o resultado sugere que os municípios não querem fazer uso ou desconhecem o arsenal jurídico à sua disposição".

\section{Considerações Finais}

Este trabalho buscou contribuir para o debate sobre o espaço urbano como um lugar permeado de contradições e conflitos. A visão constitucionalizada tornou ultrapassado o clássico conceito de propriedade e recolocou o ser humano como preocupação central do Direito, fazendo com que o conteúdo patrimonial do direito de propriedade seja contemplado secundariamente. Todo esse processo deriva do princípio constitucional da função social da propriedade, segundo o qual a existência do direito individual à propriedade fica condicionada à utilização conforme o interesse público, alcançando o escopo social deste direito privado.

O estudo do processo de formação do espaço urbano de Campos dos Goytacazes permitiu verificar que as ações realizadas pelo Estado demonstram a condução de um planejamento urbano com base na consolidação de uma área central, que se desenvolveu a partir de um núcleo urbano desenhado ainda no século XVII, e que foi fortemente influenciada pelas intervenções da indústria açucareira na economia e na sociedade. É possível, ainda, constatar o crescimento da área de expansão urbana sobre os terrenos das usinas localizadas próximas ao núcleo central, tais como Usina do Queimado e Usina Sapucaia.

Nesse processo, a terra concentrada e sob mudança de uso é a principal fonte dos vazios urbanos que vieram a ser formar, os quais contribuem para um processo de crescimento urbano segregador em relação ao acesso ao solo e aos imóveis, para os segmentos mais pobres e excluídos da população, em Campos dos Goytacazes.

$\mathrm{Na}$ cidade de Campos dos Goytacazes, as aparentes ampliações do domínio público sobre a propriedade privada e a formulação de normas legais que pregavam a atribuição de uma função social à terra urbana vêm tendo como objetivo atender aos interesses privados de transformação da terra agrícola em urbana, com a ampliação dos espaços periurbanos e a valorização desses espaços perante o mercado, contribuindo para a especulação imobiliária. 
O Poder Público Municipal fomentou políticas públicas carentes do intuito de democratização da terra e de apropriação coletiva do espaço. As políticas de urbanização voltaram-se para a higienização do espaço e a valorização estética de áreas centrais.

Nesse sentido, buscou-se, neste trabalho, apontar a importância da implementação do IPTU progressivo para justamente alcançar o cumprimento da função social da propriedade, especialmente quanto aos vazios urbanos identificados.

É importante destacar que o IPTU Progressivo, embora previsto no PDMCG/2008, em vigor, não está sendo aplicado pela Administradora em exercício, uma vez que o Poder Público municipal admitiu que o IPTU progressivo não é aplicado no município de Campos dos Goytacazes, “[...] porém, está em curso uma comissão para a implementação do IPTU progressivo no ano de 2017”, conforme Informações concedidas por Dayse Helena de Oliveira C. Bragança, Assessora Especial da Secretaria de Fazenda do Município de Campos dos Goytacazes ao tempo da realização da pesquisa (2016). Com isso, além de não atuar em benefício da justiça e equidade socioespaciais, conforme determina a legislação, age o Poder Executivo Municipal em prejuízo dos cofres públicos: permite que haja perda de receita pela admissão de cobrança do ITR em área urbana (onde deveria ser aplicado o IPTU e, nas hipóteses legais, o IPTU progressivo). Anui, também, com o exercício abusivo do direito de propriedade pelo proprietário desidioso em relação à coletividade.

A distribuição não equânime da terra reflete-se na formação de discrepâncias sociais: há espaços de segregação tanto da população de baixa renda, que se mantém em áreas menos valorizadas, quanto pelas classes mais abastadas, que se encastelam em condomínios de luxo.

Conclui-se que, se uma política pública ou um instituto jurídico urbanístico não alcança eficácia prática, deve-se ao fato de que: a) os interesses públicos se confundem aos privados em prevalência dos últimos; b) nas cidades, a força do mercado ganha mais expressão que a força do direito ou do justo; c) há necessidade de mecanismos mais eficazes de garantia da implantação de políticas públicas ou de efetivação de instrumentos de gestão urbana que objetivem a apropriação coletiva do espaço, já previstos em Lei, como o IPTU Progressivo.

Evidentemente, a falta de regulamentação dos instrumentos coercitivos que existem para dar efetividade à função social da propriedade não é uma questão a ser enfrentada apenas pelo Município de Campos dos Goytacazes.

Embora haja pouca correspondência entre os objetivos traçados nas normas e os resultados atingidos, os avanços normativos não devem ser desprezados. E, apesar de ser mais frequente a apropriação do arsenal legal pelos interesses empresariais, o uso dessas normas difunde o conhecimento 
sobre o Direito à Cidade, tornando-o mais do que apenas linguagem discursiva do Poder Público.

A intenção deste estudo não foi buscar as causas da não utilização do IPTU progressivo em Campos dos Goytacazes. Aqui é preciso destacar que há uma lacuna legal que impede a aplicação dessa penalidade constitucional, tendo em vista que o município não editou a respectiva lei específica regulamentadora.

Resta demonstrado o que já se mencionou neste trabalho: o ordenamento legal não garante o ordenamento social. Vê-se, ademais, que as ações e omissões do Estado são influenciadas pelas relações de poder que coexistem na sociedade. Sem dúvida, a positivação da função social da propriedade deve ser considerada um avanço. Entretanto, a lei que responde à questão teórica não esgota a questão da desigualdade estrutural. $\mathrm{O}$ aparato legal é resultado dos conflitos existentes e dos embates sociais; mas, é limitado, na medida em que não é hábil a solucionar as questões de fundo.

É preciso agir sobre a contradição evidenciada na produção social dos espaços urbanos: a lógica imediata do lucro, chancelada pelo empresariamento do Estado versus as necessidades coletivas. Diante da realidade posta, que nunca percamos a capacidade de nos indignar. E de agir.

\section{Referências}

ASSOCIAÇÃO BRASILEIRA DE NORMAS TÉCNICAS. NBR 12.267/1992: Fixa as condições para orientar a elaboração de Planos Diretores nos termos do artigo 182 da Constituição Federal. Rio de Janeiro: ABNT, 1992. Disponível em: <http://www.ebah.com.br/content/ABAAAA_bMAE/nbr12267-normas-elaboracao-plano-diretor $>$. Acesso em: 13 maio 2016.

BRASIL. Constituição (1988). Constituição da República Federativa do Brasil de 1988. Disponível em: <http://www.planalto.gov.br/ccivil_03/Constituicao/ ConstituicaoCompilado.htm>. Acesso em: 21 maio 2016.

Emenda Constitucional no 10, de 9 de novembro de 1964. Altera os $\operatorname{artigos}^{\circ}, 15,29,141,147$ e 156 da Constituição Federal. Disponível em: <http:// www.planalto.gov.br/ccivil_03/Constituicao/Emendas/Emc_anterior1988/ emc10-64.htm>. Acesso em: 21 maio 2016.

Ministério das Cidades. Resolução no $\mathbf{n}^{\mathbf{0}} \mathbf{3 4}$ 200. Emite as orientações e recomendações que seguem quanto ao conteúdo mínimo do Plano Diretor. 2005. Disponível em: <http://www.cidades.gov.br/images/stories/ArquivosCidades/ ArquivosPDF/Resolucoes/resolucao-34-2005_alterada.pdf $>$. Acesso em: 21 maio 2016.

Lei $\mathbf{n}^{\circ}$ 10.257, de 10 de julho de 2001. Estatuto da Cidade. Disponível em <http://www.planalto.gov.br/ccivil_03/leis/LEIS_2001/L10257. htm>. Acesso em: 21 maio 2016.

Lei Federal $\mathrm{n}^{\circ}$ 6.766, de 19 de dezembro de 1979. Dispõe sobre o parcelamento do solo urbano e dá outras providências. Disponível em: < http:// www.planalto.gov.br/ccivil_03/leis/L6766.htm>. Acesso em: 21 maio 2016. 
. Lei no 10.406, de 10 de janeiro de 2002. Institui o Código Civil. Disponível em: <http://www.planalto.gov.br/ccivil_03/leis/2002/L10406.htm>. Acesso em: 21 maio 2016.

Senado Federal. Decreto no 6.569, de 8 de junho de 1944. Determina a exibição de títulos pelos ocupantes de terras e florestas pertencentes à união e dá outras providências. Disponível em: <http://legis.senado.gov.br/legislacao/ ListaNormas.action?numero=6569\&tipo_norma=DEL\&data $=19440608 \&$ link =s>. Acesso em: 21 maio 2016 .

. Decreto n $^{\circ}$ 24.606, 6 de julho de 1934. Autoriza a desapropriação, por utilidade e necessidade pública, de terras foreiras á unido e dá outras providências. Disponível em: <http://legis.senado.gov.br/legislacao/ListaNormas. action? numero=24606\&tipo_norma=DEC\&data $=19340706 \&$ link $=\mathrm{s}>$.Acesso em: 21 maio 2016.

BOURDIEU, Pierre. O poder simbólico. Lisboa: DIFEL; Rio de Janeiro: Bertrand Brasil, 1989.

CAMPOS DOS GOYTACAZES (MUNICÍPIO). Câmara dos Vereadores. Lei no 4.156, de 16 de setembro de 1983. Institui o Código Tributário do Município de Campos e dá outras providências. Disponível em: <http://www.campos.rj.gov. br/leis-municipais.php>. Acesso em: 13 ago. 2016.

.Lei no 5.251, de 27 de dezembro de 1991. Institui o Plano Diretor do Município de Campos dos Goytacazes. Disponível em: <http://www.campos. rj.gov.br/plano-diretor.php>. Acesso em: 13 ago. 2016.

. Lei no 7.972, de 31 de março de 2008a. Institui o Plano Diretor do Município de Campos dos Goytacazes. Disponível em: <http://www.campos. rj.gov.br/plano-diretor.php>. Acesso em: 13 ago. 2016.

. Lei no 7.973, de 31 de março de 2008b. Institui a lei de Perímetros Urbanos do Município de Campos dos Goytacazes: promulgada em 31 de março de 2008. Disponível em: <http://www.campos.rj.gov.br/plano-diretor.php>. Acesso em: 13 ago. 2016.

Lei no 7.974, de 31 de março de 2008c. Institui a Lei de Uso e Ocupação do Solo Urbano do Município de Campos dos Goytacazes. Disponível em: <http://www.campos.rj.gov.br/plano-diretor.php>. Acesso em: 13 ago. 2016.

Lei no 7.975, de 31 de março de 2008d. Institui a Lei de Parcelamento do Solo do Município de Campos dos Goytacazes. Disponível em: <http://www.campos.rj.gov.br/plano-diretor.php>. Acesso em: 13 ago. 2016.

Lei Orgânica do Município de Campos dos Goytacazes, de 15 de julho de 2014. Dispõe sobre a revisão e consolidação da lei orgânica do Município de Campos dos Goytacazes/RJ. Disponível em: <fwww.campos. rj.gov.br/arquivos/LeiOrganicaDoMunicipio.pdf >. Acesso em: 13 ago. 2016. CARVALHO JÚNIOR, Pedro Humberto Bruno de. O sistema avaliatório municipal de imóveis e atributação do IPTU no Rio de Janeiro. 2010. 101 f. Dissertação (Mestrado em Economia) - Programa de Pós-Graduação em Economia, Universidade do Estado do Rio de Janeiro, Rio de Janeiro, 2010.

CONSELHO FEDERAL DE ENGENHARIA E AGRONOMIA (CONFEA). Carta Mundial do Direito à Cidade. Disponível em <http:// 
normativos.confea.org.br/downloads/anexo/1108-10.pdf>. Acesso em: 21 maio 2016.

HARVEY, David. Cidades rebeldes: do direito à cidade à revolução urbana. São Paulo: Martins Fontes, 2014.

A produção capitalista do espaço. São Paulo: Annablume, 2001.

LEFEBVRE, Henri. O Direito à Cidade. São Paulo: Centauro, 2006.

. A revolução urbana. Belo Horizonte: UFMG, 2004.

. A cidade do capital. Rio de Janeiro: DP\&A, 2001.

PINHEIRO, Mariana; ALIPRANDI, Danielly. Os espaços livres de Campos dos Goytacazes: mapeamento e categorização. In: CONFERENCIA DA REDE LUSÓFONA DE MORFOLOGIA URBANA, 4, 2015, 25-26 jun., Brasília-

DF. Anais eletrônicos... Brasília-DF: Universidade de Brasília, 2015. Disponível em: <http://www.fau.unb.br/noticias/57-pnum-2015 >. Acesso em: 12 maio 2016.

PIQUET, Rosélia. Indústria e território no Brasil contemporâneo. Rio de Janeiro: Garamond, 2007.

; RIBEIRO, Ana Clara Torres. O desenvolvimento urbano em questão. 2. ed. Rio de Janeiro: IPPUR/UFRJ, 2001.

SANTOS, Ângela Moulin Simões Penalva. Tributação imobiliária no Brasil: um difícil percurso rumo à política urbana. Finisterra: Revista Portuguesa de Geografia, Lisboa-Portugal, v. 49, n. 97, p. 1-16, maio 2014. Disponível em: <http://unuhospedagem.com.br/revista/rbeur/index.php/anais/article/ viewFile/4250/4120> . Acesso em: 10 ago. 2016.

SANTOS, Boaventura de Souza. O Estado, o direito e a questão urbana. In: FALCÃO, Joaquim de Arruda (Org.). Invasões urbanas: conflito de direito de propriedade. 2. ed. Rio de Janeiro: FGV, 2008. p. 11-86.

SINGER, Paul. O uso do solo urbano na economia capitalista. Boletim Paulista de Geografia, São Paulo, n. 57, p. 77-92, 1980. Disponível em: < https://www.agb. org.br/publicacoes/index.php/boletim-paulista/article/view/1044>. Acesso em: 13 jul. 2016.

SUPREMO TRIBUNAL FEDERAL. Enunciado sumular no 668. Brasília: STF, 2003. Disponível em: <http:/www.stf.jus.br/portal/cms/verTexto.asp?servi co=jurisprudenciaSumula $>$. Acesso em: 13 maio 2016.

VAINER, Carlos. Cidade de Exceção: reflexões a partir do Rio de Janeiro. 2011. Disponível em: <https://br.boell.org/sites/default/files/downloads/carlos_vainer_ ippur_cidade_de_excecao_reflexoes_a_partir_do_rio_de_janeiro.pdf $>$.Acesso em: 15 jul. 2016.

VASCONCELLOS, Eduardo Alcântara. Transporte público urbano nos países em desenvolvimento: reflexões e propostas. 3. ed. São Paulo: Annablume, 2000.

Submetido em: 06/03/2017

Aceito em: 15/04/2018 


\title{
THE URBAN VOIDS AND THE RIGHTTO THE CITY: CHALLENGES OFTHE IMPLEMENTATION OFTHE PROGRESSIVE IPTU IN THE CITY OF CAMPOS DOS GOYTACAZES/RJ
}

\begin{abstract}
The present study aims to analyze the city as a social production, originated from the complex and conflicting action of social agents, who represents different interests. It revolves around the capitalist dynamics in the construction of the urban space and how these structures are organized. Using the city of Campos dos Goytacazes/RJ as scenario, this study clarifies the role and importance of progressive IPTU (urban land tax) in democratic access to urban land, as recommended by Brazilian law, as an instrument to guarantee the Right to the City. The study analyzed the legal and political factors that favor and allow the existence of urban voids in the city perimeter, in regions valued and equipped with collective urban equipment, and in the regions that will be valued by public and/or private action. It was demonstrated how the private initiative appropriates the public investments for the valorization of its enterprises, which evidences the performance of capital in the configuration of the constructed environment. In Campos dos Goytacazes, the inapplicability of the progressive IPTU, as one of the instruments for fulfilling the social function of property, particularly in coping with the speculative urban voids, demonstrates the complexity of the interests at stake. How has the municipal government dealt with the issue of urban voids and progressive IPTU in law and practice? The study dedicated to understand some important aspects of the structure and dynamics of the urban space in Campos dos Goytacazes, highlights the role of urban planning, and, in this, reinforce the potential of IPTU implementation as a means of reintegrating existing urban voids in the city, making possible to mitigate the impacts of urban land concentration and real estate speculation, aggravating factors of socio-spatial segregation.
\end{abstract}

Keywords: City. Conflicts. Urban voids. Right to the City. Progressive IPTU. 